\title{
PERFORMANCE OF PERVIOUS CONCRETE REINFORCED WITH POLYPROPYLENE FIBERS
}

\author{
Jorge Luiz Almeida Mussado, Eng. (UEL) \\ Berenice Martins Toralles, Dra. (UEL) \\ Gersson F. B. Sandoval, PhD Student (UEL)
}

\section{INTRODUCTION}

Sustainable development has been increasingly considered by society since it is a model that involves economic growth linked with socio-environmental thinking.

In the ecological issue, we seek to minimize the damage caused to the environment, but this has become a great challenge for the political area since in the big cities of Brazil there is a very great economic and population growth. This growth is not only a negative factor, but the way it has been happening in short time frames has generated more and more environmental problems.

Among these environmental problems related to construction, it has been the growth of sealed area in urban areas due to the construction of highways 100\% waterproof, sidewalks and real estate. As an example of this growth in the city of São Carlos, when there was a growth of $22 \%$ of the population between 1996 and 2006, there was an increase of impervious surface in $36.4 \%$ (COSTA et al., 2013), and this situation is very similar to large cities.

These environmental problems should be highly avoided, because with them occur physical harm to families who are homeless, as happened in September 2013 in the state of Santa Catarina, when floods hit 92 cities, with more than 31000 people homeless and 4000 affected households (SILVA, 2013). This, of course, has not only as a reason the sealed area, but this adds to the situation from getting worse.

Considering this type of environmental impacts by the management of surface runoff it is important to implement the use of permeable materials such as the pervious concrete.

Considering what has been said, this study aims to evaluate the mechanical and hydraulic properties of pervious concrete with the addition of fibers and the use of superplasticizer additive.

The materials used to fabricate the pervious concrete mixture are Portland cement, coarse aggregates, water, superplasticizer, and fiber. The cement used was Portland
Cement CP II-Z-32; (Brazilian denomination). The coarse aggregate is crushed basaltic with a maximum size of $12.5 \mathrm{~mm}$. The superplasticizer additive was MR-5122 polycarboxylate base; The fibers used in this study was short polypropylene fibers and finally potable water as recommended by the literature [1,2].

Figure 1 presents the granulometric curve of the aggregates used.

Figure 1 - Granulometric curve

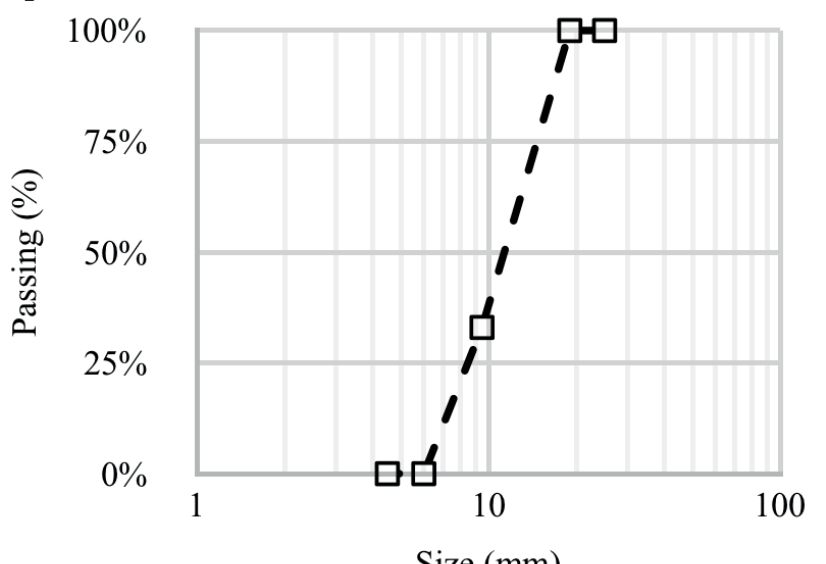

Size $(\mathrm{mm})$

Source: The authors

The pervious concrete was mixed in a conventional mixer with a capacity of 150 liters. The total mixing time was 5 minutes [3] and then the specimens were molded using cylinder molds $(100 \times 200 \mathrm{~mm})$. The mixtures were compacted using a proctor hummer with 10 drops in a unique layer.

To test the mechanical behavior two tests were made compressive and flexural strength by the Brazilian standards NBR 5739/2007 and NBR 15805/2010.

The results for mechanical behavior are shown in Table 1. These tables contain the mean value, the standard deviation and the coefficient of variation. 
Table 1 - Compressive Strength Results

\begin{tabular}{|l|l|l|l|l|}
\hline Concrete & C0.31 & C0.31F & C0.26A & C0.26AF \\
\hline \multirow{3}{*}{$\begin{array}{l}\text { Compressive } \\
\text { Strength } \\
(\mathbf{M P a})\end{array}$} & 5.7 & 6.3 & 5.7 & 6.0 \\
\cline { 2 - 5 } & 6.7 & 6.7 & 4.8 & 6.1 \\
\cline { 2 - 5 } & 5.3 & 7.2 & 5.8 & 8.1 \\
\cline { 2 - 5 } & 5.9 & 5.2 & 4.7 & 5.6 \\
\hline Average & 5.9 & 6.4 & 5.3 & 6.5 \\
\hline $\boldsymbol{\sigma}$ & 0.6 & 0.9 & 0.6 & 1.1 \\
\hline CV (\%) & 10.0 & 13.4 & 11.1 & 17.4 \\
\hline
\end{tabular}

As shown in Table 1, the high compressive strength was C0.26AF, explained by its low $\mathrm{w} / \mathrm{c}$ ratio and the use of superplasticizer. then the values of the other 3 mixtures were very close because this property is highly related to the granulometry of the aggregates and this was the same in all the mixtures. the range of values found for the 4 mixtures agrees with what is found in the literature review [4-6].

The results of hydraulic behavior are shown in Table 2 and 3 . These tables contain the mean value, the standard deviation and the coefficient of variation

Table 2 - Porosity Results

\begin{tabular}{|l|l|l|l|l|}
\hline Concrete & C0.31 & C0.31F & C0.26A & C0.26AF \\
\hline Porosity (\%) & 26,2 & 26,6 & 29,7 & 26,5 \\
\hline $\boldsymbol{\sigma}$ & 2,4 & 1,1 & 1,0 & 0,8 \\
\hline CV (\%) & 9,2 & 4,1 & 3,4 & 3,0 \\
\hline
\end{tabular}

As shown in Table 2 the porosity values are in the range of literature review[4,7-9]. The values found for the 4 mixtures are very close since the porosity is related to the granulometry, the paste content and the compacting of the material and in all cases, this was the same.

In Table 3 are shown the permeability results obtained by the constant head permeability test.

Table 3 - Permeability Results

\begin{tabular}{|l|l|l|l|l|}
\hline Concrete & $\mathbf{C 0 . 3 1}$ & $\mathbf{C 0 . 3 1 F}$ & $\mathbf{C 0 . 2 6 A}$ & C0.26AF \\
\hline \multirow{3}{*}{$\mathbf{k}(\mathbf{m m} / \mathbf{s})$} & 35,0 & 31,0 & 35,0 & 32,0 \\
\cline { 2 - 5 } & 16,0 & 32,0 & 31,0 & 34,0 \\
\cline { 2 - 5 } & 41,0 & 35,0 & 24,0 & 33,0 \\
\hline Average & 30,7 & 32,7 & 30,0 & 33,0 \\
\hline $\boldsymbol{\sigma}$ & 13,1 & 2,1 & 5,6 & 1,0 \\
\hline CV (\%) & 42,6 & 6,4 & 18,6 & 3,0 \\
\hline
\end{tabular}

As shown in Table 3 no significant difference in permeability values found for the four mixtures. These values agree with those found for porosity since they are directly proportional properties.

The CV values founded to C0.31 are really high but were presented because one of the specimens had an accumulation of paste in the base, therefore there was a representative decrease in the coefficient of permeability affecting the final average value.

\section{CONCLUSIONS}

In terms of compressive strength was more preponderant the relation $\mathrm{w} / \mathrm{c}$ than the addition of fibers in the mixture.

The addition of fibers improved the tensile strength but was affected by the maximum aggregate size used, the use of aggregates with a maximum size of $9.5 \mathrm{~mm}$ would have helped to better distribute tension stresses.

The correlation for the hydraulic properties could not be established due to the use of a single granulometry

\section{ACKNOWLEDGMENTS}

To the State University of Londrina (UEL), to the center of technology and urbanism (CTU) and to the laboratory of materials to offer all the available resources for the development of this study.

\section{REFERENCES}

P.D. Tennis, M.L. Leming, D.J. Akers, Pervious Concrete Pavements, 2004.

G.F. Barreto Sandoval, DESEMPENHO DO CONCRETO POROSO COM AGREGADOS SUSTENTÁVEIS, Universidade Estadual de Londrina, 2014.

G.F.B. Sandoval, I. Galobardes, R.S. Teixeira, B.M. Toralles, Comparison between the falling head and the constant head permeability tests to assess the permeability coefficient of sustainable Pervious Concretes, Case Stud. Constr. Mater. 7 (2017) 317-328. doi:10.1016/j. cscm.2017.09.001.

O. Deo, N. Neithalath, Compressive behavior of pervious concretes and a quantification of the influence of random pore structure features, Mater. Sci. Eng. A. 528 (2010) 402-412. doi:10.1016/j.msea.2010.09.024.

R. Zhong, K. Wille, Linking pore system characteristics to the compressive behavior of pervious concrete, 
Cem. Concr. Compos. 70 (2016) 130-138. doi:10.1016/j. cemconcomp.2016.03.016.

C. Gaedicke, A. Torres, K.C.T. Huynh, A. Marines, A method to correlate splitting tensile strength and compressive strength of pervious concrete cylinders and cores, Constr. Build. Mater. 125 (2016) 271-278. doi:10.1016/j. conbuildmat.2016.08.031.

W.D. Martin, B.J. Putman, Comparison of methods for measuring porosity of porous paving mixtures, Constr. Build. Mater. 125 (2016) 299-305. doi:10.1016/j. conbuildmat.2016.08.038.

C. Lian, Y. Zhuge, S. Beecham, The relationship between porosity and strength for porous concrete, Constr. Build. Mater. 25 (2011) 4294-4298. doi:10.1016/j. conbuildmat.2011.05.005.

W.D. Martin, N.B. Kaye, B.J. Putman, Impact of vertical porosity distribution on the permeability of pervious concrete, Constr. Build. Mater. 59 (2014) 78-84. doi:10.1016/j. conbuildmat.2014.02.034. 